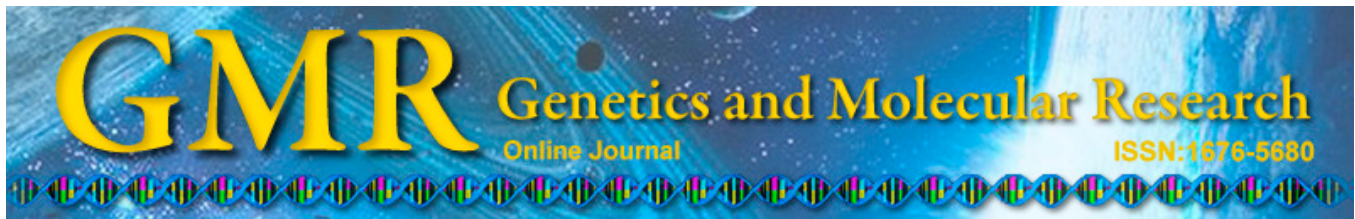

\title{
A $\mathrm{Cu} / \mathrm{Zn}$ superoxide dismutase from Jatropha curcas enhances salt tolerance of Arabidopsis thaliana
}

\author{
Z.B. Liu ${ }^{1}$, W.J. Zhang ${ }^{1}$, X.D. Gong ${ }^{3}$, Q. Zhang ${ }^{4}$ and L.R. Zhou ${ }^{2,3}$ \\ ${ }^{1}$ Key Laboratory of Bio-Resources and Eco-Environment, \\ Ministry Education, College of Life Sciences, Sichuan University, Chengdu, China \\ ${ }^{2}$ Architecture \& Environment Department, Sichuan University, Chengdu, \\ Sichuan, China \\ ${ }^{3}$ Civil Engineering Department, University of British Columbia, Vancouver, \\ BC, Canada \\ ${ }^{4}$ Panzhihua University, Panzhihua, Sichuan, China \\ Corresponding author: L.R. Zhou \\ E-mail: zhoulr@mail.ubc.ca
}

Genet. Mol. Res. 14 (1): 2086-2098 (2015)

Received April 9, 2014

Accepted October 23, 2014

Published March 20, 2015

DOI http://dx.doi.org/10.4238/2015.March.20.19

\begin{abstract}
Superoxide dismutases (SODs) are involved in protecting plants against diverse biotic and abiotic stresses. In the present study, a novel $\mathrm{Cu} / \mathrm{Zn}$-SOD gene $(\mathrm{JcCu} / \mathrm{Zn}-\mathrm{SOD})$ was cloned from Jatropha curcas L. Quantitative reverse transcription-polymerase chain reaction analysis revealed that $J_{c} C u / Z n-S O D$ is constitutively expressed in different tissues of $J$. curcas and induced under $\mathrm{NaCl}$ treatment. To characterize the function of this gene with respect to salt tolerance, the construct p35S:JcCu/Zn-SOD was developed and transformed into Arabidopsis using Agrobacterium-mediated transformation. Compared with wild-type, transgenic plants over-expressing $J_{c} \mathrm{Cu} / \mathrm{Zn}$-SOD showed enhanced tolerance to salt stress during germination, seedling establishment, and growth in terms of longer root, larger rosette area, and a larger number of leaves in addition to higher SOD activity levels
\end{abstract}


under $\mathrm{NaCl}$ stress. In addition, over-expression of $J_{c} \mathrm{Cu} / \mathrm{Zn}-\mathrm{SOD}$ resulted in lower monodialdehyde content in transgenic Arabidopsis compared to wild-type plants under the same $\mathrm{NaCl}$ stress. Therefore, $J c C u / Z n-S O D$ can increase a plant salt stress tolerance potentially by reducing oxidant injury.

Key words: Abiotic stress tolerance; Anti-oxidative enzymes; $\mathrm{Cu} / \mathrm{Zn}-\mathrm{SOD} ; \mathrm{NaCl}$ stress; Jatropha curcas

\section{INTRODUCTION}

Soil salinity, particularly $\mathrm{NaCl}$ content, is principally regarded as an inherent problem in irrigated agriculture, and limits plant growth and crop yield worldwide (Zhu, 2001). Increased salinization of arable land has devastating global effects, with $30 \%$ land loss predicted to occur within the next 25 years and up to $50 \%$ by the year 2050 (Wang et al., 2003). Under salt stress, both the osmotic and ionic balances are severely damaged, resulting in the accumulation of reactive oxygen species (ROS) (Patade et al., 2012), which is toxic to cells at high concentration by causing oxidative damage to membrane lipids, proteins, and nucleic acids (Price et al., 1989; Moran et al., 1994). To protect against oxygen-mediated injuries, plants have developed different strategies, either by suppressing ROS generation or scavenging ROS that they have already produced (Apel and Hirt, 2004).

Superoxide dismutases (SOD; EC: 1. 15. 1. 1), a family of metalloenzymes, is one of the most important enzymes in the plant defense system against oxidative stress, and it occurs ubiquitously in every cell of all plant types (Mittler, 2002). As the first-line defense against oxidative damage, SOD catalyzes the conversion or dismutation of toxic superoxide anion radicals to molecular oxygen and hydrogen peroxide. Therefore, increased SOD expression can protect plants against physical stresses (salinity, chilling, drought, and high light intensity). It has been reported that SOD over-expression in some transgenic plants enhanced their tolerances to stresses (Lee et al., 2007; Tseng et al., 2007). Thus, SOD is considered to be a key enzyme in the regulation of intracellular ROS levels and in the maintenance of normal physiological conditions under oxidative stress (Mittler, 2002).

Jatropha curcas L., commonly known as physic nut, is a $\mathrm{NaCl}$-resistant tropical shrub or small tree that belongs to the Euphorbiaceae family. The lifespan of $J$. curcas is up to 50 years, and it can grow in mining areas where soils are contaminated by heavy metals (Openshaw, 2000). Recently, this plant has attracted considerable attention because its seeds are an ideal raw material for biodiesel production (Mohibbe Azam et al., 2005; Fairless, 2007; Achten et al., 2008). Moreover, J. curcas can be used as a source of food, soap, cosmetics, pesticides, and anticancer medicine (Makkar and Becker, 2009). Previous studies showed that SODs may be the most important factors for J. curcas against salt, drought, and heavy metal stress (Gao et al., 2009, 2010). However, in contrast to other plants, the antioxidant response to oxidative and environmental stress has not yet been well-characterized in $J$. curcas at the molecular level.

In the present study, a $J c C u / Z n-S O D$ gene was cloned and sequenced from $J$. curcas. We detected the expression of $J c C u / Z n-S O D$ in different tissues of $J$. curcas. To characterize the role of $J c C u / Z n-S O D$ in vivo, the gene was introduced into Arabidopsis and over-expressed. Furthermore, differences between transgenic and wild-type (WT) Arabidopsis plants were compared under $\mathrm{NaCl}$ stress. 


\section{MATERIAL AND METHODS}

\section{Plant materials and treatments}

Mature seeds, flowers, leaves, stems, roots, and silique of $J$. curcas were collected in the summer from Panzhihua city of Sichuan Province, China, and instantly frozen in liquid nitrogen. Mature seeds were immersed in $70 \%$ ethanol for $5 \mathrm{~min}$ and then $0.1 \%$ mercuric choride for $10 \mathrm{~min}$. Seeds were rinsed with distilled water soaked for 24-36 h at room temperature and sown in trays filled with sand for germination and growth.

Arabidopsis thaliana seeds were surface-sterilized and sown on plates containing 20 $\mathrm{mL}$ MS medium (Murashige and Skoog, 1962). Seeds were stratified in the dark at $4^{\circ} \mathrm{C}$ for 2 days and then transferred to a tissue culture box at $22^{\circ} \mathrm{C}$ (16-h light/ 8 -h dark).

\section{Cloning and sequencing of the $J c C u / Z n-S O D$ gene}

Total RNA was extracted from plant tissues using the Trizol reagent (Invitrogen, Carlsbad, CA, USA) following manufacturer instructions. First-strand cDNA was synthesized using Superscript II (Invitrogen). A specific fragment of $J_{c} C u / Z n-S O D$ was amplified using 2 degenerate primers, $J C S O D 1$ and $J C S O D 2$ (Table 1), which were designed based on the conserved regions of the corresponding genes from other plants. The polymerase chain reaction (PCR) was performed as follows: $94^{\circ} \mathrm{C}$ for $3 \mathrm{~min} ; 32$ cycles at $94^{\circ} \mathrm{C}$ for $30 \mathrm{~s}, 50^{\circ} \mathrm{C}$ for $30 \mathrm{~s}$, and $72^{\circ} \mathrm{C}$ for $60 \mathrm{~s}$; and a final extension step of $72^{\circ} \mathrm{C}$ for $2 \mathrm{~min}$. The PCR fragment was purified using an Agarose Gel DNA Purification Kit (Takara, Shiga, Japan), and ligated into the pMD18-T vector (Takara). Sequence analysis was performed by Invitrogen in Shanghai. The 5'- and 3'-ends of $J c C u / Z n-S O D$ were obtained using a BD SMART RACE cDNA Amplification Kit (Clontech, Mountain View, CA, USA) with the specific primers JcSOD3, JcSOD4, $J_{C S O D 5}$, and $J_{C S O D 6}$ (Table 1).

\begin{tabular}{|c|c|}
\hline Primers & Sequences $\left(5^{\prime}-3^{\prime}\right)$ \\
\hline JCSOD1 & $\mathrm{AT}(\mathrm{T} / \mathrm{C}) \mathrm{TC}(\mathrm{A} / \mathrm{C}) \mathrm{A}(\mathrm{T} / \mathrm{G}) \mathrm{CCG}(\mathrm{A} / \mathrm{T}) \mathrm{ACAA}(\mathrm{A} / \mathrm{C}) \mathrm{AAGACACA}$ \\
\hline JCSOD2 & $\mathrm{AT}(\mathrm{T} / \mathrm{C}) \mathrm{G}(\mathrm{C} / \mathrm{T}) \mathrm{CAAC}(\mathrm{A} / \mathrm{G}) \mathrm{ACC}(\mathrm{T} / \mathrm{C}) \mathrm{AC}(\mathrm{A} / \mathrm{G}) \mathrm{AGC}(\mathrm{T} / \mathrm{C}) \mathrm{A}$ \\
\hline JCSOD3 & ACTAAGTTCATGCCCACCCTTTCA \\
\hline JCSOD4 & GTGCTCTTCCGACTACTGCATTTGG \\
\hline JCSOD5 & CCGTCATGCGGGTGACCTGGGAAC \\
\hline JCSOD6 & TAGTTGCTAACGCTGATGGGGTGGC \\
\hline JCSOD7 & TCAAACTTCCTCGTCAATCGC \\
\hline JCSOD8 & CTGTTGTGGGACCATCGTCTT \\
\hline Actin-F & ATGAGCTTCGAGTTGCACCA \\
\hline Actin-R & AGCATCAGTGAGATCACGAC \\
\hline
\end{tabular}

\section{Real-time PCR}

Total RNA was extracted from different tissues or leaves by $200 \mathrm{mM} \mathrm{NaCl}$ treatment. Real-time PCR was performed using $1 \mu \mathrm{g}$ total RNA for reverse transcription. The RNAs were quantified using the Quantity One 1-D Analysis Software (Bio-Rad, Hercules, CA, USA). Expression levels of genes were determined using the iCyclerTM IQ Real-Time PCR Detection System (Bio-Rad) according to the QuantiTect SYBR Green PCR Kit instruction manual and 
were analyzed using the iCyclerTM Real-Time Detection System software (version 3.0). A $J_{c} C u / Z n-S O D$ fragment (168 bp) was amplified using the gene-specific primers $J_{c S O D} 7$ and $J c S O D 8$ (Table 1). J. curcas actin, amplified using the primers Actin-F and Actin-R (Table 1), giving a product of $180 \mathrm{bp}$, was used as a reference to normalize $J c C u / Z n-S O D$ cDNA levels. $J_{c C} C u / Z n-S O D$ cDNA levels were normalized with those of actin in the same samples and the final relative cDNA amounts of $J c C u / Z n-S O D$ were the means of 3 replicates.

\section{Plasmid construction and Arabidopsis transformation}

Full-length $J c C u / Z n-S O D$ was cut from $p M D 18-J_{c} C u / Z n$-SOD using BamHI and $\mathrm{SacI}$ restriction sites, and subcloned into the cognate sites of pBI121. The $J_{c} C u / Z n-S O D$ gene was located between the CaMV35S promoter and the NOS 3'poly (A) signal to generate 35S: $J_{c} \mathrm{Cu} / \mathrm{Zn}-\mathrm{SOD}$. The construct was transformed into Agrobacterium (GV3101). A. thaliana was transformed by Agrobacterium using the floral-dip procedure (Clough and Bent, 1998). Transformants were selected for their ability to grow on $1 / 2 \mathrm{MS}$ medium containing $50 \mu \mathrm{g} /$ $\mathrm{mL}$ kanamycin and by PCR. T3 generation plants were used in all experiments unless other indicated.

\section{Salt tolerance assay}

For the germination test, WT and transgenic Arabidopsis seeds were surface-sterilized, seeded on plates containing MS medium with $150 \mathrm{mM} \mathrm{NaCl}$ or without $\mathrm{NaCl}$. The plates were incubated at $4^{\circ} \mathrm{C}$ for 2 days and then the temperature was increased to $22^{\circ} \mathrm{C}$. The germination rates were scored every day. For the plant growth assay, half of the 7-day-old seedlings grown on MS medium were transferred onto plates containing $150 \mathrm{mM} \mathrm{NaCl}$. The seedlings were allowed to grow on this medium for 3 weeks. Finally, the root length, rosette area, number of leaves, and morphology of individual plants were observed and calculated.

\section{Total SOD activity}

After 3 weeks of growth in the presence or absence of $150 \mathrm{mM} \mathrm{NaCl}$, the WT and $J_{c} C u / Z n-S O D$ transgenic Arabidopsis plants were analyzed for SOD activity as previously described (Alonso et al., 2001). Leaves were homogenized in $50 \mathrm{mM}$ potassium-phosphate buffer, $\mathrm{pH} 7.5$, and then centrifuged at $15,000 \mathrm{~g}$ for $30 \mathrm{~min}$ at $4^{\circ} \mathrm{C}$. The supernatant was added to a reaction mixture containing $50 \mathrm{mM}$ phosphate buffer, $\mathrm{pH} 7.0,13 \mathrm{mM}$ methionine, $75 \mathrm{mM}$ nitro blue tetrazolium, $100 \mathrm{mM}$ EDTA. The reaction was started by adding $2 \mu \mathrm{M}$ riboflavin and placing the tubes under $15 \mathrm{~W}$ fluorescent lamps for $15 \mathrm{~min}$. The control set of reaction mixtures was kept in the dark. Activity was calculated by determining absorbance at $560 \mathrm{~nm}$.

\section{Determination of lipid peroxidation}

Lipid peroxidation was determined by measuring the amount of malondialdehyde

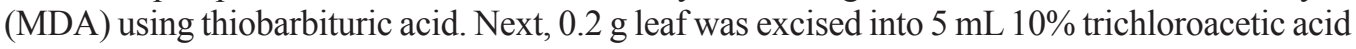
containing $0.5 \%$ thiobarbituric acid and $0.5 \%$ Triton X100 and homogenized using a cold pestle and mortar. The mixture was placed in boiling water bath for $30 \mathrm{~min}$ and then quickly cooled in an ice bath. After centrifugation at $13,000 \mathrm{~g}$ for $10 \mathrm{~min}$, the absorbance of the supernatant was 
determined at 532 and $600 \mathrm{~nm}$ by atomic emission spectrophotometry (Cao et al., 2009).

\section{Statistical analyses}

The SPSS software version 15.0 (SPSS Inc., Chicago, IL, USA) was used for statistical analysis. Analysis of variance was performed followed by the Duncan multiple comparison tests. Statistically significant differences $(\mathrm{P}<0.05)$ are reported in the figures.

\section{RESULTS}

\section{Cloning of the $J c C u / Z n-S O D$ gene}

Several $\mathrm{Cu} / \mathrm{Zn}$-SODs have been reported in many plants, and sequence analysis revealed numerous conserved regions (Abreu and Cabelli, 2010). These sequences were used to design degenerate primers to clone $\mathrm{Cu} / \mathrm{Zn}$-SOD from J. curcas. A 265-bp fragment was amplified from leaf cDNA. A cDNA, referred to as $J_{c} C u / Z n-S O D$, was obtained by random amplification of cDNA ends-PCR and consisted of $901 \mathrm{bp}$, including 25-bp 5'-untranslated and 145-bp 3'-untranslated regions. The cloned $J_{c} C u / Z n-S O D$ contained an open reading frame encoding a polypeptide of 243 amino acids with a calculated molecular mass of $24.85 \mathrm{kDa}$ and an isoelectric point of 6.57. Sequence alignment of the deduced amino acids (Figure 1) was found to share approximately $70 \%$ identical amino acids with its homologs in Populus trichocarpa, Fragaria vesca, Ricinus communis, and Theobroma cacao. Phylogenetic analysis indicated that $J c C u / Z n-S O D$ is most closely related to $C u / Z n-S O D$ from Ricinus communis (Figure 2). The sequence of JcCu/Zn-SOD was deposited in the NCBI GenBank under accession No. KF268341.

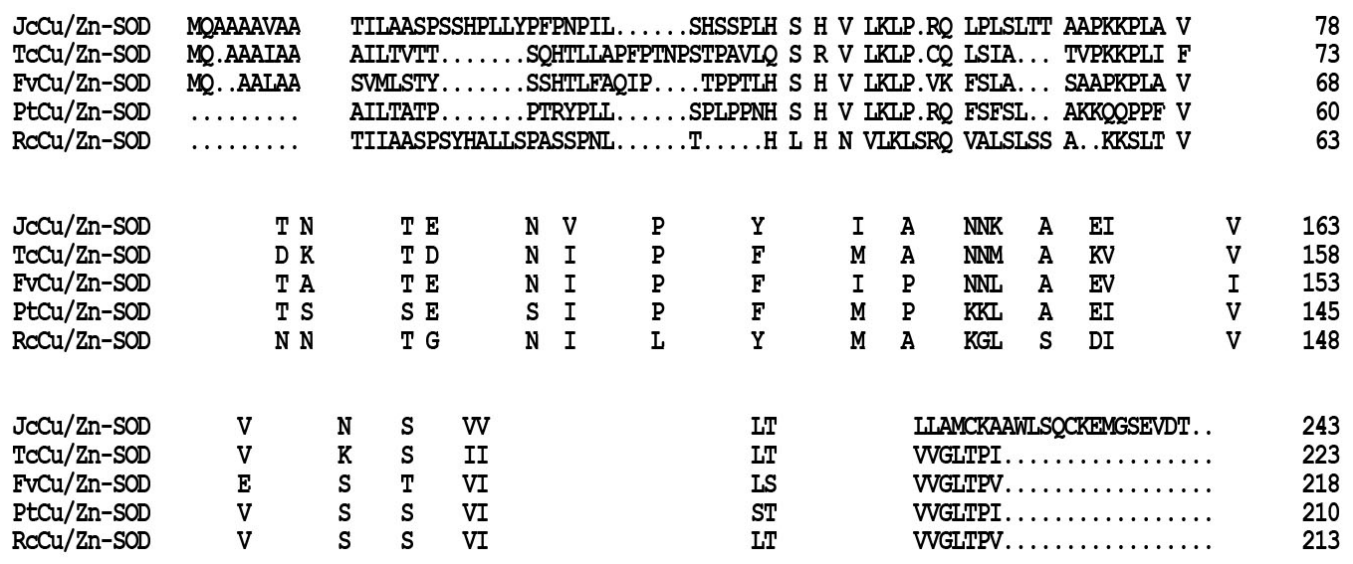

Figure 1. Comparison of the amino acid sequence of $\mathrm{Cu} / \mathrm{Zn}$-SOD from several plant species using the MEGA 5.0 software. The GenBank accession No. and name of these sequences are as follows: JcCu/Zn-SOD, J. curcas Cu/ Zn-SOD (KF268341); TcCu/Zn-SOD, Theobroma cacao Cu/Zn-SOD (EOY33683.1); FvCu/Zn-SOD, Fragaria vesca $\mathrm{Cu} / \mathrm{Zn}$-SOD (XP_004287550.1); PtCu/Zn-SOD, Populus trichocarpa Cu/Zn-SOD (EEF10665.1); RcCu/ZnSOD, Ricinus communis Cu/Zn-SOD (EEF38668.1). Identical amino acids are highlighted in black and similar residues are in gray. 


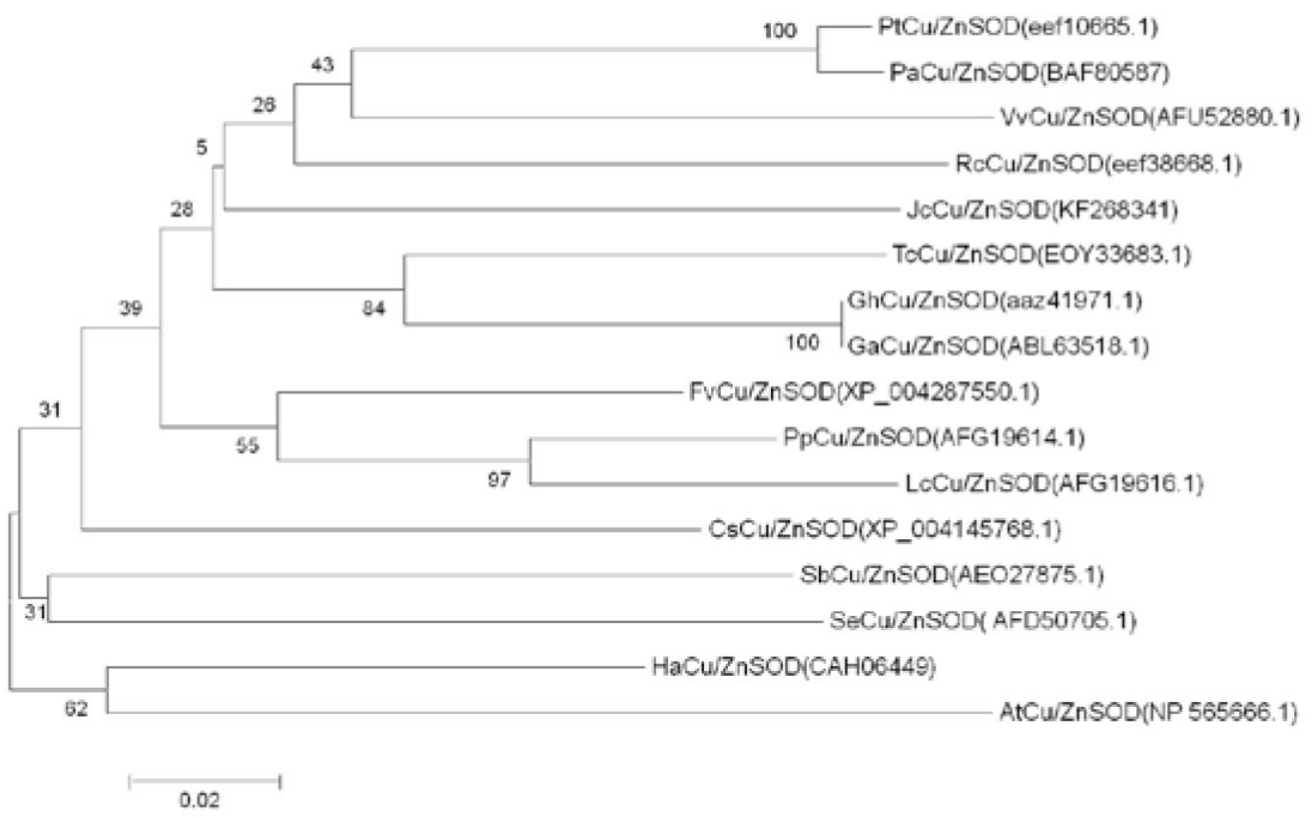

Figure 2. Phylogenetic tree for the amino acid sequences of $\mathrm{Cu} / \mathrm{Zn}$-SODs. The tree was constructed using the neighbor-joining method. Plant sources and GenBank accession No. are indicated. Jc = Jatropha curcas; $\mathrm{Pt}=$ Populus trichocarpa $; \mathrm{Pa}=$ Populus alba $; \mathrm{Vv}=$ Vitis vinifera $; \mathrm{Rc}=$ Ricinus communis; $\mathrm{Tc}=$ Theobroma cacao; $\mathrm{Gh}=$ Gossypium hirsutum $; \mathrm{Ga}=$ Gossypium arboreum $; \mathrm{Fv}=$ Fragaria vesca $; \mathrm{Pp}=$ Prunus persica $; \mathrm{Lc}=$ Litchi chinensis; $\mathrm{Cs}=$ Cucumis sativus; $\mathrm{Sb}=$ Scutellaria baicalensis; $\mathrm{Se}=$ Salicornia europaea $; \mathrm{Ha}=$ Helianthus annuus; At $=$ Arabidopsis thaliana . The scale bar represents 2 residue differences per 100 amino acids.

\section{Expression profile of $\mathrm{JcCu} / \mathrm{Zn}-\mathrm{SOD}$}

Quantitative real-time PCR analysis indicated that the $J c C u / Z n-S O D$ gene was expressed in all $J$. curcas tissues examined (root, stem, leaf, flower, and silique). Moreover, the expression of $J_{c} C u / Z n-S O D$ was significantly higher in the leaf than in other tissues (Figure $3 \mathrm{~A})$.

Previous studies showed that $\mathrm{Cu} / \mathrm{Zn}$-SOD levels were increased under $\mathrm{NaCl}$ stress in A. thaliana (Attia et al., 2011). In this study, to determine whether the expression of $J c C u$ / $\mathrm{Zn}-\mathrm{SOD}$ is regulated by $\mathrm{NaCl}$, the mRNA accumulation profile was determined under 200 $\mathrm{mM} \mathrm{NaCl}$ treatment. As indicated in Figure 3B, $J c C u / Z n-S O D$ expression began increasing within $6 \mathrm{~h}$, peaked at $18 \mathrm{~h}$, and subsequently decreased. The results showed that $J_{c} C u / Z n-S O D$ expression was closely related to $\mathrm{NaCl}$ stress.

\section{Over-expression of $\mathrm{JcCu} / \mathrm{Zn}-\mathrm{SOD}$ in Arabidopsis plants}

The induction of $J_{c} C u / Z n-S O D$ expression by $200 \mathrm{mM} \mathrm{NaCl}$ prompted us to analyze its function in $\mathrm{NaCl}$ stress resistance. Accordingly, we developed $J c C u / Z n-S O D$ homozygous transgenic lines in $A$. thaliana. Among the 36 putative T0 transgenic lines, only 8 lines segregated for $J c C u / Z n-S O D$ in 3:1 ratio in the T1 generation. Subsequently, $J_{c} C u / Z n-S O D$ levels 
were detected in transgenic plants by PCR and semi-qPCR. Three transgenic lines (S3, S12, and S26) that expressed relatively higher $J c C u / Z n-S O D$ levels were used for further analysis (Figure 4A and B).

(A)

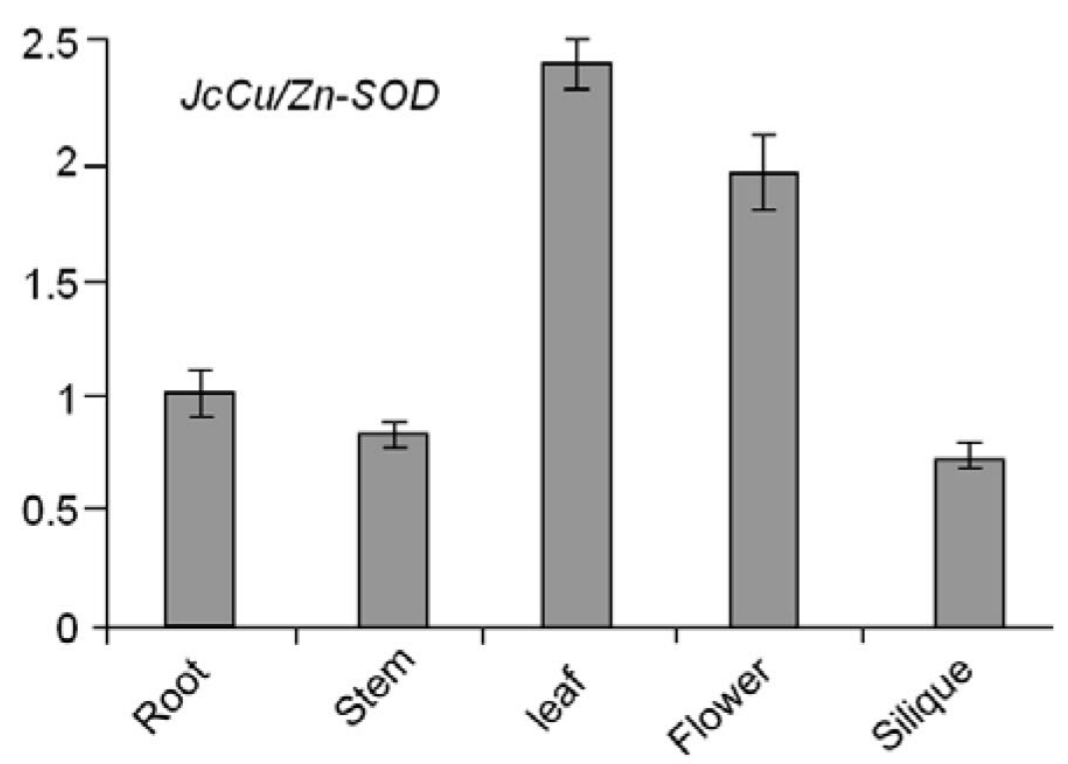

(B)

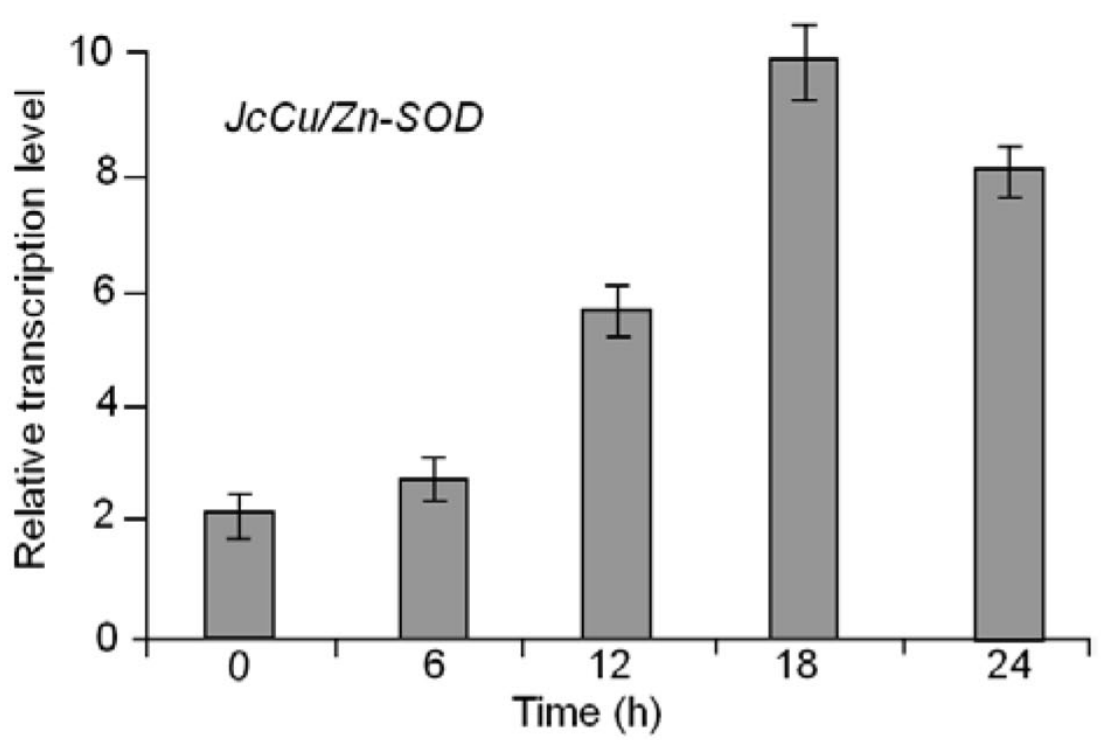

Figure 3. Expression of $J_{c} C u / Z n-S O D$. A. q-PCR analysis of $J c C u / Z n-S O D$ in different tissues of Jatropha curcas. Total RNA was extracted from the root, stem, leaf, and silique of wild-type plants. B. q-PCR analysis of $J_{c} C u /$ $Z n-S O D$ expression in $J$. curcas exposed to $\mathrm{NaCl}$. Total RNAs were isolated from 4-week-old leaves of $J$. curcas treated at $200 \mathrm{mM} \mathrm{NaCl}$ and duration from 0-24 h. Transcripts of actin were used as a control. Error bars indicate the standard deviation of the mean $(\mathrm{N}=3)$. Three replicates were analyzed. 


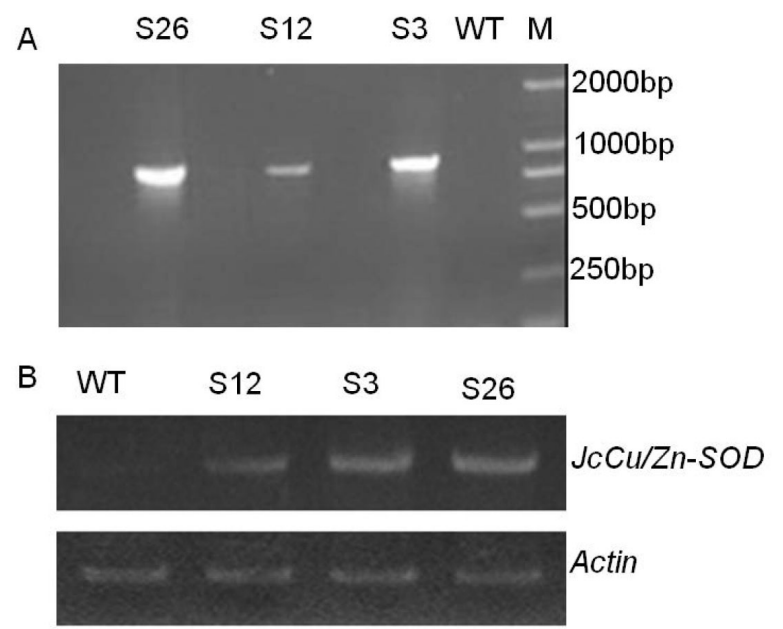

Figure 4. Detection of the transgene from kanamycin-resistant lines. A. Confirmation of $J_{c} \mathrm{Cu} / \mathrm{Zn}-\mathrm{SOD}$ transgenic Arabidopsis plants by PCR. WT, wild-type plants; S3, S12, and S26, independently transformed plant lines; $M$, DNA marker (DL2000). B. Semi-quantitative RT-PCR analysis of $J c C u / Z n-S O D$ in transgenic lines. Actin was used as a reference to show that equal amounts of RNA were used in the analysis. WT, wild-type plants; S3, S12, and S26, independently transformed plant lines.

\section{$\mathrm{JcCu} / \mathrm{Zn}-\mathrm{SOD}$ enhances the resistance of plants to $\mathrm{NaCl}$ stress}

In Arabidopsis, salt sensitivity was most evident during seed germination and subsequent seedling growth (Gao et al., 2003). In our study, no difference between transgenic lines and WT in germination percentage was observed when seeds were maintained on MS medium without $\mathrm{NaCl}$ (Figure 5A and $\mathrm{B}$ ) while a significant difference between those two groups of Arabidopsis plants was found in the rate of germination following supplementation with 150 $\mathrm{mM} \mathrm{NaCl}$. Three days after spotting, transgenic lines began germinating, whereas the WT germinated on the 5th day. Eleven days later, the germination rate of WT was $45 \%$, while the germination rates of S3, S12, and S26 transgenic lines were 91, 83, and 96\%, respectively (Figure 5B and D).

In the post-germination phase, the seeds continuously growing on medium plates without $\mathrm{NaCl}$ supplementation showed morphology and growth characteristics of transgenic seedlings similar to those of WT (Figure 6A). In contrast, under $150 \mathrm{mM} \mathrm{NaCl}$ treatment, WT seedlings showed retarded growth, whereas the growth of transgenic seedlings (S3, S12, and S26) was slightly restrained. Moreover, primary root length and lateral root number of the WT lines were dramatically reduced compared to transgenic lines (Figure 6B).

After 3 weeks of plant growth, both the number of leaves and area of rosette were measured. No significant difference was observed in number of leaves in the transgenic plants compared to controls under normal growth conditions. However, under $150 \mathrm{mM} \mathrm{NaCl}$ stress, the number of leaves on transgenic plants S3, S12, and S26 were 2, 2, and 4, respectively, which was more than their corresponding controls (Figure 7A). It was also observed that the rosette area of the transgenic lines was similar compared with WT on normal MS medium. However, it was more pronounced in transgenics than in WT plants under $\mathrm{NaCl}$ stress conditions. In transgenic plants, the rosette area of S3, S12, and S26 was 57, 37, and 67\%, respec- 

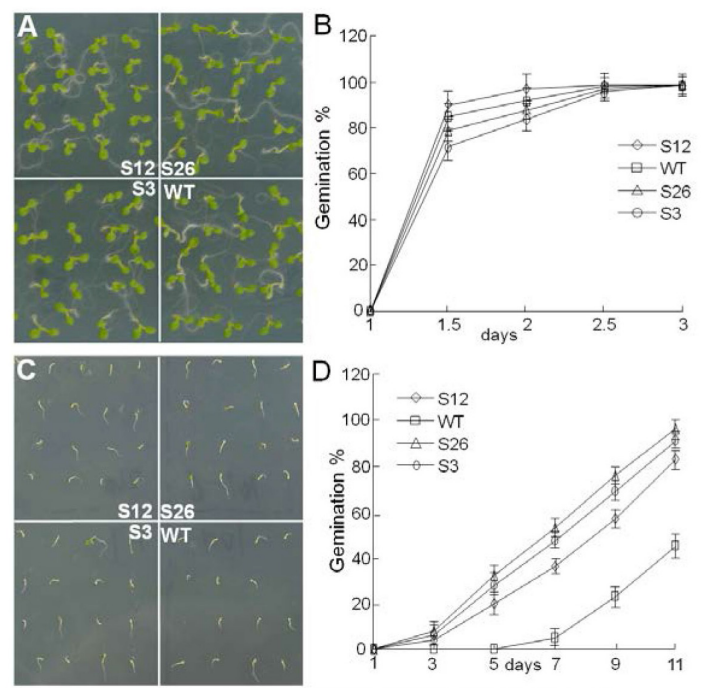

Figure 5. Effect of salt $(\mathrm{NaCl})$ stress on germination of $J c C u / Z n-S O D$ transgenic Arabidopsis seeds. Seeds were germinated in MS medium supplemented in the presence or absence of $\mathrm{NaCl}$. Photos were taken on the 11th day without $\mathrm{NaCl}(\mathbf{A})$ or $150 \mathrm{mM} \mathrm{NaCl}$ stress (C). The germination rate was determined for a period as indicated under normal condition (B) or NaCl-treated (D). $\mathrm{N}=50 \pm 5$. The data are reported as the mean value of 3 individual experiments.WT, non-transgenic Arabidopsis; S3, S12, and S26, independent $J c C u / Z n-S O D$ transgenic lines.
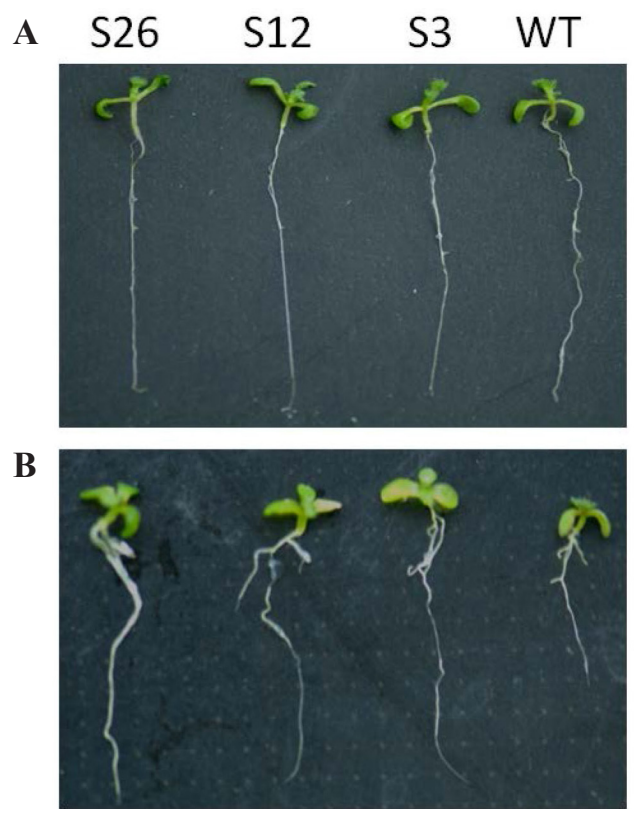

Figure 6. Growth of wild-type and transgenic Arabidopsis seedlings (S3, S12, and S26) on MS medium supplemented or not with $\mathrm{NaCl}$. Seven-day-old seedlings were transformed onto MS agar plates supplemented with different concentrations of $\mathrm{NaCl}$ and allowed to grow for 2 weeks. A. Normal condition; B. $150 \mathrm{mM} \mathrm{NaCl}$. 


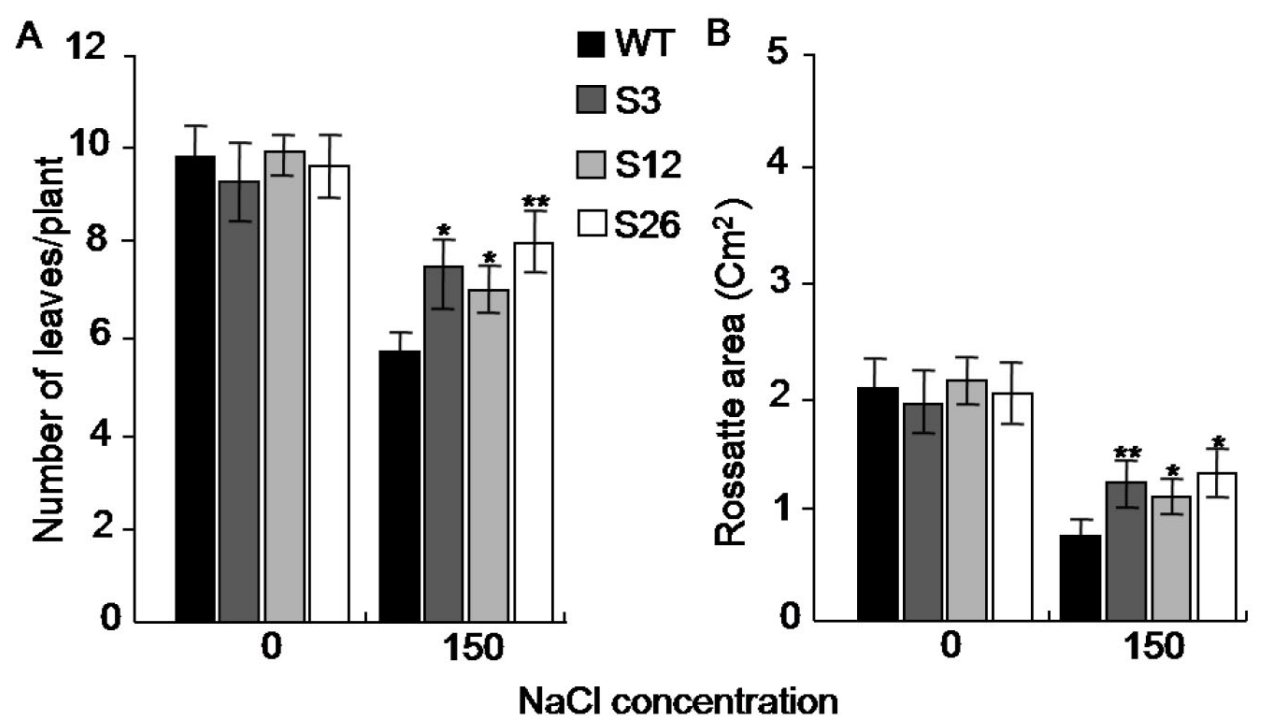

Figure 7. Over-expression of $J c C u / Z n-S O D$ gene in Arabidopsis improves number of leaves and rosette area. Wildtype and transgenic plants transferred to MS agar plates supplemented with $150 \mathrm{mM} \mathrm{NaCl}$ or without $\mathrm{NaCl}$. After 3 weeks of growth on these plates, the number of leaves (A) and rosette area (B) were recorded. Data are reported as mean values \pm standard deviation of 3 replications. The single and double asterisks represent significant difference determined by the Student $t$-test at $\mathrm{P}<0.05$ and $\mathrm{P}<0.01$, respectively.

tively; values that were higher than in WT (Figure 7B).

These results suggested that over-expression of $J_{c} C u / Z n-S O D$ enhanced tolerance to salt stress in transgenic plants.

\section{Higher SOD activity in transgenic Arabidopsis plants under NaCl stress}

It was hypothesized that the increased tolerance to salt stress during Arabidopsis growth resulted from higher SOD levels. As expected, total SOD activity in transgenic plants was significantly higher than in WT after 3 weeks of growth under $150 \mathrm{mM} \mathrm{NaCl}$ treatment. On MS medium without salt stress, the SOD activities of S3, S12, and S26 were 4.1, 3.9, and $4.5 \mathrm{U} / \mathrm{mg}$ protein, respectively, and that of WT was 3.5. Under $150 \mathrm{mM} \mathrm{NaCl}$ stress, activity in the WT was only 5.4, while the 3 transgenic lines examined, S3, S12, and S26, showed SOD levels of 10.2, 9.8, and 11.6, respectively (Figure 8A).

\section{Transgenic plants suffered less MDA than WT}

Salt stress causes rapid and excessive accumulation of ROS in plant cells, which further causes a lipid peroxidation chain reaction. MDA is the principal by-product of lipid oxidation. In our study, there was no significant difference in MDA content between WT and transgenic lines without $\mathrm{NaCl}$ treatment. However, under $150 \mathrm{mM} \mathrm{NaCl}$ treatment, MDA content in transgenic over-expressing lines was lower than that in WT. Lines S3, S12, and S26 exhibited approximately 22,15 , and $28 \%$, respectively, lower MDA concentration than the non-transformed control (Figure 8B). 


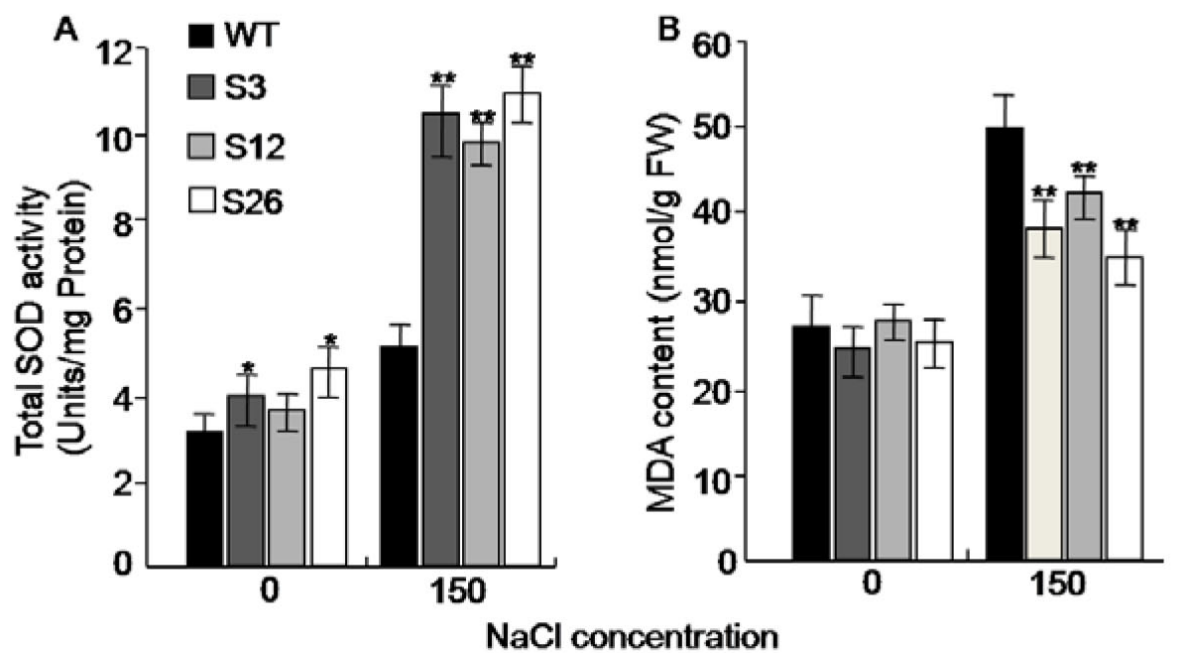

Figure 8. Changes in SOD activity (A) and MDA content (B) in wild-type and transgenic lines under salt stress. Plants were treated for 3 weeks with $150 \mathrm{mM} \mathrm{NaCl}$ or were untreated and sampled for measurement. Data are reported as mean values \pm standard deviation of 3 replications. The single and double asterisks represent significant difference determined by the Student $t$-test at $\mathrm{P}<0.05$ and $\mathrm{P}<0.01$, respectively.

\section{DISCUSSION}

It has been reported that increased SOD activity is positively correlated with the tolerance to different stresses such as low/high temperature, drought, salinity, high light intensity, and ozone (Ueda et al., 2013). In the present study, we isolated a novel $C u / Z n-S O D$ from $J$. curcas. Sequence alignment of $J c C u / Z n-S O D$ with other plants revealed that the gene shares highly identity with other reported $\mathrm{Cu} / \mathrm{Zn}$-SOD proteins (Figure 1), suggesting that $J c C u$ / $Z n-S O D$ likely has the same function as other reported homologous proteins. Quantitative real-time PCR analysis showed that the $J_{c} C u / Z n-S O D$ gene was expressed in all J. curcas tissues examined and increased under $\mathrm{NaCl}$ stress (Figure $3 \mathrm{~A}$ and $\mathrm{B}$ ). These findings generally agree with those other studies reporting increased $\mathrm{Cu} / \mathrm{Zn}$-SOD expression in plants exposed to salt stress (Hernandez et al., 1999; Wang et al., 2010). However, no significant changes in $\mathrm{Cu}$ / $\mathrm{Zn}$-SOD mRNA levels were observed in other experiments under $\mathrm{NaCl}$ treatment (MenezesBenavente et al., 2004; Jithesh et al., 2006). Differences between $\mathrm{Cu} / \mathrm{Zn}$-SOD may allow them to function in diverse responses.

The seeds of Arabidopsis plant over-expressing the $J_{c} C u / Z n-S O D$ gene exhibited a higher germination rate and better survival ability than those of WT under $\mathrm{NaCl}$ stress (Figure 5-7). These results agreed with those of previous studies (Badawi et al., 2004; Gill et al., 2010; Diaz-Vivancos et al., 2013). Saline induced an increase in the ROS level, leading to seed deterioration (Xi et al., 2010). Under salt stress, ROS production may exceed the removal ability of native antioxidant enzymes, thus harming the germinating seeds and resulting in slower germination in WT seeds. In contrast, in transgenic lines, over-expression of $J c C u / Z n-S O D$ may help the plant to maintain safe ROS levels by scavenging over-produced ROS. Moreover, without salt stress, similar germination response and early seedling establishment were ob- 
served in transgenic and WT seeds, suggesting that over-expression of the $J_{c} C u / Z n S O D$ gene to a moderate level did not affect the growth of transgenic plants.

Although $J_{c} C u / Z n-S O D$ over-expression in transgenic lines was driven by the high activity of cauliflower mosaic virus $35 \mathrm{~S}$ promoter, SOD activity was only slightly higher in transgenic lines than in the WT without salt treatment. In contrast, the activity was much higher in transgenic lines compared to in WT under $\mathrm{NaCl}$ stress (Figure 8A). These results suggest that post-transcriptional or post-translational regulation occurs for the $J_{c} C u / Z n-S O D$ gene, which has been reported in Arabidopsis (Sunkar et al., 2006; Xi et al., 2010).

Salt stress causes extensive lipid peroxidation. Therefore, the level of MDA, produced during peroxidation of membrane lipids, is often used as an indicator of salt-induced oxidative damage (Gossett et al., 1996). Our results showed that transgenics had significantly lower MDA contents compared to WT under salt stress (Figure 8B), and over-expression of $J c C u$ / $\mathrm{Zn}$-SOD can eliminate salt-induced ROS by decomposing it into water and oxygen, thus helping the plant to overcome the stress induced by $\mathrm{NaCl}$. Several studies have reported upregulation of the antioxidative system decreases MDA content to protect plant against stress (Gill and Tuteja, 2010).

In conclusion, our results demonstrated that the over-expression of $\mathrm{JcCu} / \mathrm{Zn}-\mathrm{SOD}$ enhances the salt resistance during the plant life without negatively affecting development. Transgenic Arabidopsis plants exhibited higher levels of SOD activity WT and may reduce MDA content under $\mathrm{NaCl}$ stress. Importantly, over-expression of $J c \mathrm{Cu} / \mathrm{Zn}-\mathrm{SOD}$ in crops may be useful for promoting their resistance in high soil salinity areas.

\section{ACKNOWLEDGMENTS}

Research supported by the National Natural Science Foundation of China (\#31300996, \#51109147, \#J1103518) and the Science and Technology Agency of Sichuan Province (\#2012JY0016).

\section{REFERENCES}

Abreu IA and Cabelli DE (2010). Superoxide dismutases - a review of the metal-associated mechanistic variations. Biochim. Biophys. Acta 1804: 263-274.

Achten WMJ, Verchot L, Franken YJ and Mathijs E (2008). Jatropha bio-diesel production and use. Biomass Bioenergy 32: 1063-1084.

Alonso R, Elvira S, Castillo FJ and Gimeno BS (2001). Interactive effects of ozone and drought stress on pigments and activities of antioxidative enzymes in Pinus halepensis. Plant Cell Environ. 24: 905-916.

Apel K and Hirt H (2004). Reactive oxygen species: metabolism, oxidative stress, and signal transduction. Annu. Rev. Plant Biol. 55: 373-399.

Attia H, Karray N, Msilini N and Lachaâl M (2011). Effect of salt stress on gene expression of superoxide dismutases and copper chaperone in Arabidopsis thaliana. Biol. Plantarum 55: 159-163.

Badawi GH, Yamauchi Y, Shimada E and Sasaki R (2004). Enhanced tolerance to salt stress and water deficit by overexpressing superoxide dismutase in tobacco (Nicotiana tabacum) chloroplasts. Plant Sci. 166: 919-928.

Cao YJ, Wei Q, Liao Y, Song HL, et al. (2009). Ectopic overexpression of AtHDG11 in tall fescue resulted in enhanced tolerance to drought and salt stress. Plant Cell Rep. 28: 579-588.

Clough SJ and Bent AF (1998). Floral dip: a simplified method for Agrobacterium-mediated transformation of Arabidopsis thaliana. Plant J. 16: 735-743.

Diaz-Vivancos P, Faize M, Barba-Espin G, Faize L, et al. (2013). Ectopic expression of cytosolic superoxide dismutase and ascorbate peroxidase leads to salt stress tolerance in transgenic plums. Plant Biotechnol. J. 11: 976-985.

Fairless D (2007). Biofuel: the little shrub that could-maybe. Nature 449: 652-655. 
Gao X, Ren Z, Zhao Y and Zhang H (2003). Overexpression of SOD2 increases salt tolerance of Arabidopsis. Plant Physiol. 133: 1873-1881.

Gao S, Yan R, Wu J, Zhang FL, et al. (2009). Growth and antioxidant responses in Jatropha curcas cotyledons under lead stress. Z Naturforsch. C 64: 859-863.

Gao S, Ou-yang C, Tang L, Zhu JQ, et al. (2010). Growth and antioxidant responses in Jatropha curcas seedling exposed to mercury toxicity. J. Hazard. Mater. 182: 591-597.

Gill SS and Tuteja N (2010). Reactive oxygen species and antioxidant machinery in abiotic stress tolerance in crop plants. Plant Physiol. Biochem. 48: 909-930.

Gill T, Sreenivasulu Y, Kumar S and Ahuja PS (2010). Over-expression of superoxide dismutase exhibits lignification of vascular structures in Arabidopsis thaliana. J. Plant Physiol. 167: 757-760.

Gossett DR, Banks SW, Millhollon EP and Lucas MC (1996). Antioxidant response to NaCl stress in a control and an $\mathrm{NaCl}-$ Tolerant cotton cell line grown in the presence of paraquat, buthionine sulfoximine, and exogenous glutathione. Plant Physiol. 112: 803-809.

Hernandez JA, Campillo A, Jimenez A and Alarcon JJ (1999). Response of antioxidant systems and leaf water relations to $\mathrm{NaCl}$ stress in pea plants. New Phytol. 141: 241-251.

Jithesh MN, Prashanth SR, Sivaprakash KR and Parida A (2006). Monitoring expression profiles of antioxidant genes to salinity, iron, oxidative, light and hyperosmotic stresses in the highly salt tolerant grey mangrove, Avicennia marina (Forsk.) Vierh. by mRNA analysis. Plant Cell Rep. 25: 865-876.

Lee SH, Ahsan N, Lee KW, Kim DH, et al. (2007). Simultaneous overexpression of both CuZn superoxide dismutase and ascorbate peroxidase in transgenic tall fescue plants confers increased tolerance to a wide range of abiotic stresses. J. Plant Physiol. 164: 1626-1638.

Makkar HPS and Becker K (2009). Jatropha curcas, a promising crop for the generation of biodiesel and value-added coproducts. Eur. J. Lipid Sci. Technol. 111: 773-787.

Menezes-Benavente L, Teixeira FK, Alvim Kamei CL and Margis-Pinheiro M (2004). Salt stress induces altered expression of genes encoding antioxidant enzymes in seedlings of a Brazilian indica rice (Oryza sativa L.). Plant Sci. 166: 323-331.

Mittler R (2002). Oxidative stress, antioxidants and stress tolerance. Trends Plant Sci. 7: 405-410.

Mohibbe Azam M, Waris A and Nahar NM (2005). Prospects and potential of fatty acid methyl esters of some nontraditional seed oils for use as biodiesel in India. Biomass Bioenergy 29: 293-302.

Moran JF, Becana M, Iturbe-Ormaetxe I and Frechilla S (1994). Drought induces oxidative stress in pea plants. Planta 194: 346-352.

Murashige T and Skoog F (1962). A revised medium for rapid growth and bio assays with tobacco tissue cultures. Physiol. Plant 15: 473-497.

Openshaw K (2000). A review of Jatropha curcas: an oil plant of unfulfilled promise. Biomass Bioenergy 19: 1-15.

Patade VY, Bhargava S and Suprasanna P (2012). Effects of $\mathrm{NaCl}$ and iso-osmotic PEG stress on growth, osmolytes accumulation and antioxidant defense in cultured sugarcane cells. Plant Cell Tiss. Org. 108: 279-286.

Price AH, Atherton NM and Hendry GA (1989). Plants under drought-stress generate activated oxygen. Free Radic. Res. Commun. 8: 61-66.

Sunkar R, Kapoor A and Zhu JK (2006). Posttranscriptional induction of two Cu/Zn superoxide dismutase genes in Arabidopsis is mediated by downregulation of miR398 and important for oxidative stress tolerance. Plant Cell 18: 2051-2065.

Tseng MJ, Liu CW and Yiu JC (2007). Enhanced tolerance to sulfur dioxide and salt stress of transgenic Chinese cabbage plants expressing both superoxide dismutase and catalase in chloroplasts. Plant Physiol. Biochem. 45: 822-833.

Ueda Y, Uehara N, Sasaki H, Kobayashi K, et al. (2013). Impacts of acute ozone stress on superoxide dismutase (SOD) expression and reactive oxygen species (ROS) formation in rice leaves. Plant Physiol. Biochem. 70: 396-402.

Wang W, Vinocur B and Altman A (2003). Plant responses to drought, salinity and extreme temperatures: towards genetic engineering for stress tolerance. Planta 218: 1-14.

Wang YC, Qu GZ, Li HY, Wu YJ, et al. (2010). Enhanced salt tolerance of transgenic poplar plants expressing a manganese superoxide dismutase from Tamarix androssowii. Mol. Biol. Rep. 37: 1119-1124.

Xi DM, Liu WS, Yang GD, Wu CA, et al. (2010). Seed-specific overexpression of antioxidant genes in Arabidopsis enhances oxidative stress tolerance during germination and early seedling growth. Plant Biotechnol. J. 8: 796-806.

Zhu JK (2001). Plant salt tolerance. Trends Plant Sci. 6: 66-71. 